\title{
ECONOMY
}

\section{THE ASSESSMENT OF THE INTERCONNECTION BETWEEN ECONOMIC GROWTH AND INFLATION IN THE REPUBLIC OF ARMENIA}

\author{
Artur Karapet Ayrumyan \\ PhD student of the Chair of "Theory of Economics" ASUE \\ Armenia, Yerevan
}

DOI: https://doi.org/10.31435/rsglobal_wos/30042019/6441

\author{
ARTICLE INFO \\ Received: 15 February 2019 \\ Accepted: 17 April 2019 \\ Published: 30 April 2019

\section{KEYWORDS} \\ inflation targeting, \\ economic growth, GDP gap, \\ new Keynesian Philip's Curve, \\ inflation expectations.
}

\begin{abstract}
Considering the connection between inflation and real growth one should take into account the interruptions of time interactions. Thus, current GDP gap is likely to have a greater influence on the coming era. On account of that time-lag impacts of indicators should be studied.
\end{abstract}

Citation: Artur Karapet Ayrumyan. (2019) The Assessment of the Interconnection Between Economic Growth and Inflation in the Republic of Armenia. International Academy Journal Web of Scholar. 4(34). doi: 10.31435/rsglobal_wos/30042019/6441

Copyright: (C) 2019 Artur Karapet Ayrumyan. This is an open-access article distributed under the terms of the Creative Commons Attribution License (CC BY). The use, distribution or reproduction in other forums is permitted, provided the original author(s) or licensor are credited and that the original publication in this journal is cited, in accordance with accepted academic practice. No use, distribution or reproduction is permitted which does not comply with these terms.

Considering the connection between inflation and real growth one should take into account the interruptions of time interactions. Thus, current GDP gap is likely to have a greater influence on the coming era. On account of that time-lag impacts of indicators should be studied.

The results of figure 1 can be divided into two parts. The first part introduces zero or T0 period effects of previous 8 years ( 2 years) on real GDP gaps (the effect of each lag, separately and/but not total). This segment can be called lag impacts of GDP gap on inflation.

The second part naturally introduces zero or TP period effects of coming 8 years ( 2 years) of separate GDP gaps on inflation. This segment can be represented as future impacts of expectations about GDP on inflation developments.

Indeed, the signs of lag impacts of GDP gaps are logical, i.e. GDP gap still affects inflation in four quarters. It is worthy to mention that the relation is relatively high only for T0 and T-1 periods. Accordingly correlation coefficients are 0,17 and 0,14 .

The expectation effects for GDP future gaps on inflations are much more interesting. The figure outlines that the correlation between immediate quarterly gap and the zero-year inflation is still positive. It illustrates that future expectations of income growth cause inflationary pressures which is absolutely logical. A different outlining is observed for the next quarterly expectations. Starting from the second quarter, the correction of all the remaining time gaps and inflation is negative and significant, therefore. 


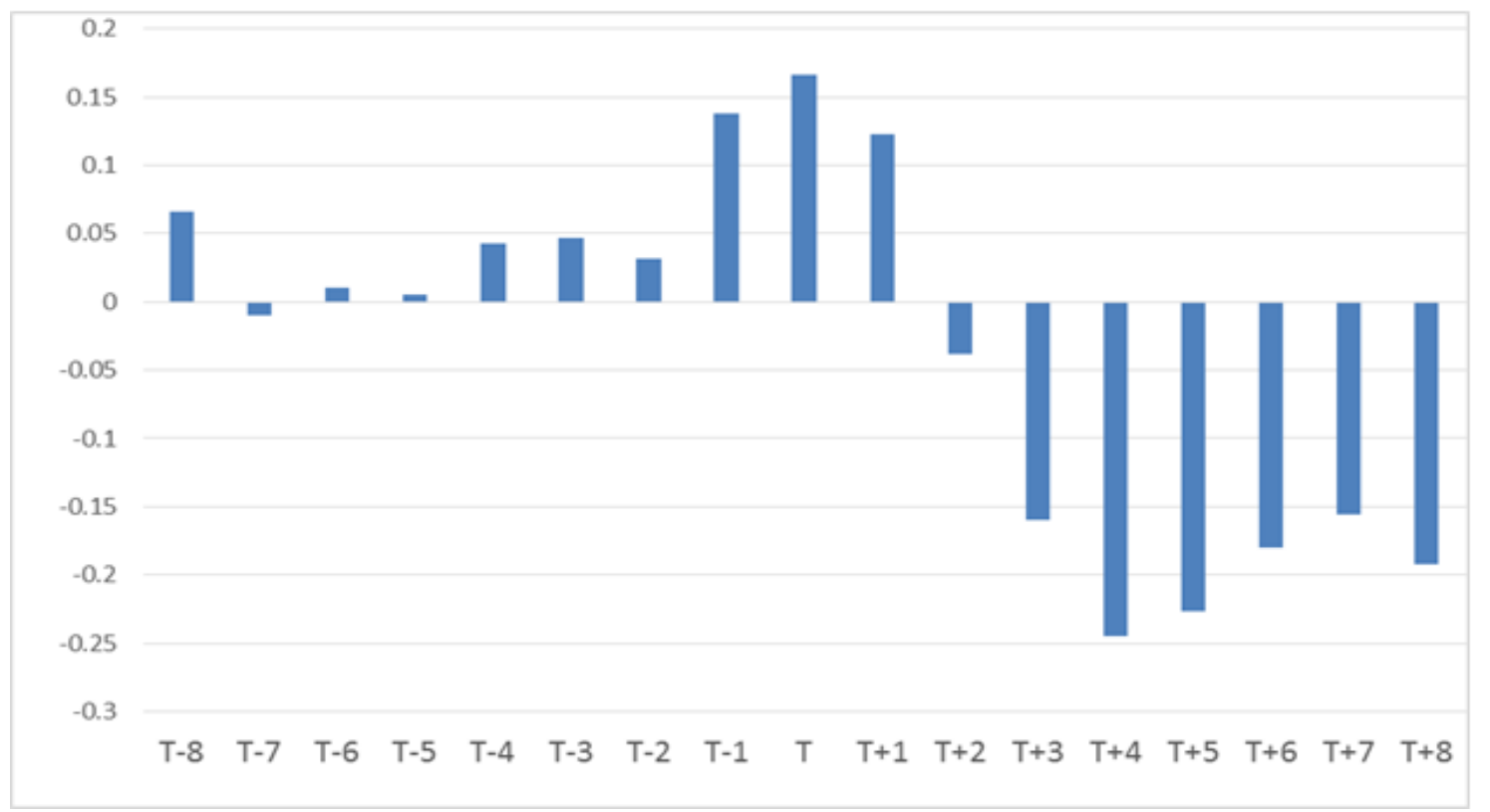

Fig. 1. Correlation coefficients between target deviation of real inflation and GDP gap in different lags ${ }^{1}$

The results make us suppose that our country has somewhat different viewpoint about the mechanism of expectations' influence on inflation. For instance, the central bank running an imminent policy and pays a great attention to expectations, correspondingly predicting positive developments/trends in the economy for several quarters (GDP positive gap) and accordingly price restrictions. The bank responds to the expectations only "today", tightening monetary policy, which has a negative impact on the current inflation rate.

Currently the interconnection between economic growth and inflation are of utmost importance and are studied among new Keynesian economists. The new Keynesian Philip's Curve has become one of the most important equations among dynamic stochastic general equilibrium models.

Now, it is apparent, that we can form the connection between inflation and GDP gap based on the quarterly data of 2001-2018 through scatter plot. It can help us to make linear linkage between inflation and real GDP gap.



Fig. 2. Linear link between real inflation and GDP gap

\footnotetext{
${ }^{1}$ It represents correlation coefficients between GDP gap and zero period in different lags
} 
The figure represents the indications of quarterly inflation and GDP gap respectively. It can be stated that the drift points from general tendency are not high. And two important conclusions can be drawn upon: First, equation consent of the linear linkage is 3,9. This means that the average real inflation is $4 \%$ for the whole period, i.e. there are deviations from the target and sometimes the deviation has been high, yet in an average it has been targeted. Second, the influence of GDP gap in inflation is not high, but it is positive, thereupon. One percent enlargement of GDP gap brings the rise of 0,12 percentage point of inflation.

As a matter of fact, the aforementioned analyses can be considered short-term linkage of inflation- economic growth. For getting exact results, the yearly data are to be used not having also seasonal adjustment. Inasmuch as our state has small amounts yearly data on aforementioned indicators (just 18 points), we have tried to fill in / enlarge data base with another states' lines. It has been done for expanding the number of observations. Resultantly, there are more than 500 observation.

We have tried to choose states that are similar to Armenia within the context of economy and that realize inflation targeting strategy (about three dozen countries). The aim is that can share the numerical results of the mentioned states in our state's economy.

In this case, the results again show the relation of short-term inflation and economic growth (see Figure 3)

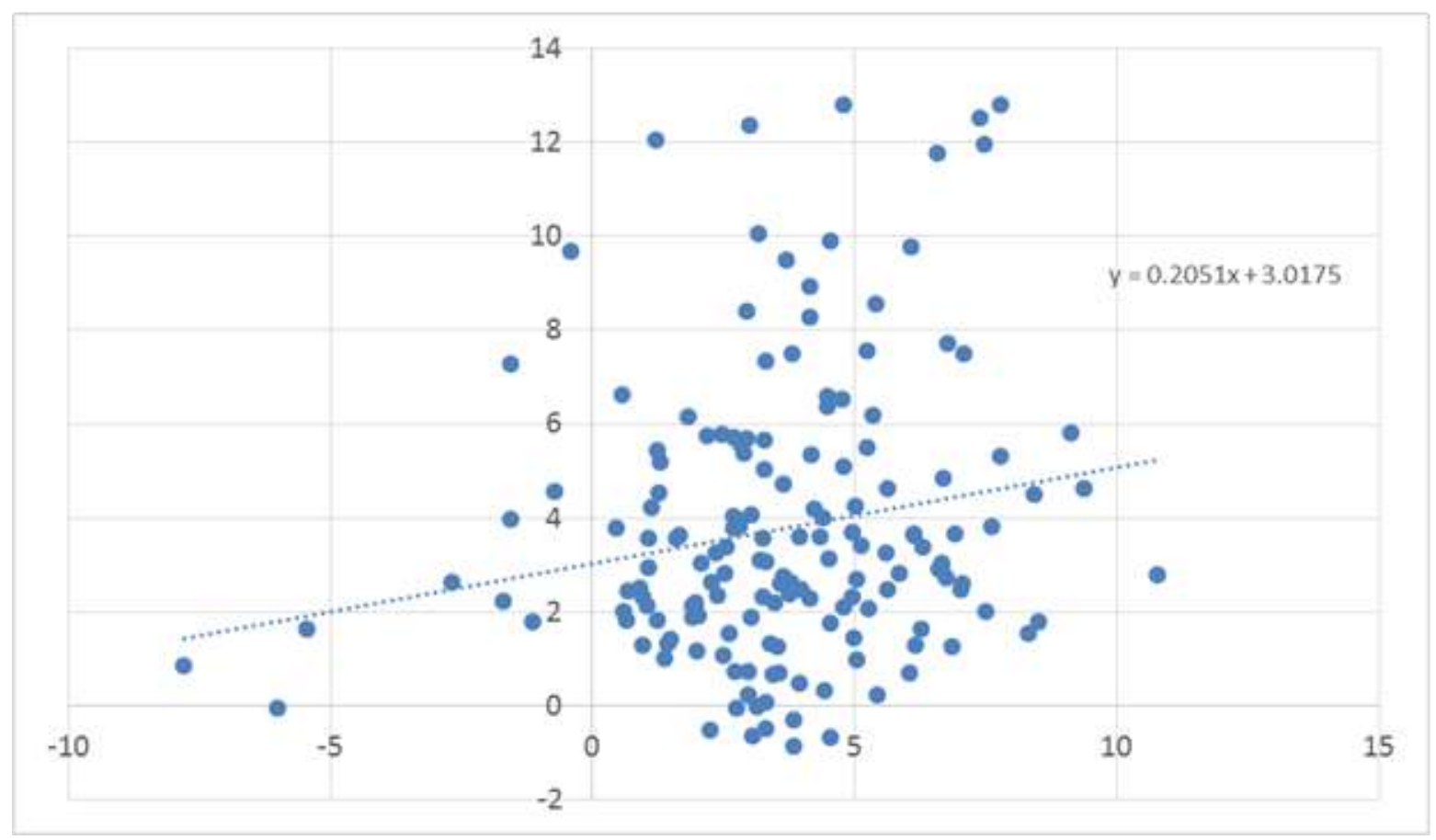

Fig. 3. Short-term inflation- economic growth link in the selected countries

It should be mentioned that in the short-term period the connection between inflation and economic growth is positive. Therefore, in long-term period (as the theory of economy states) the given interconnection is lost. It also is obvious through the states that we have chosen. Let's represent average data of the 17 chosen states in the scope of inflation and economic grows indicators. For each state there is one point (two data).

Figure 3.1.6 shows that inflation- economic growth relation in long-term period is zero then. 


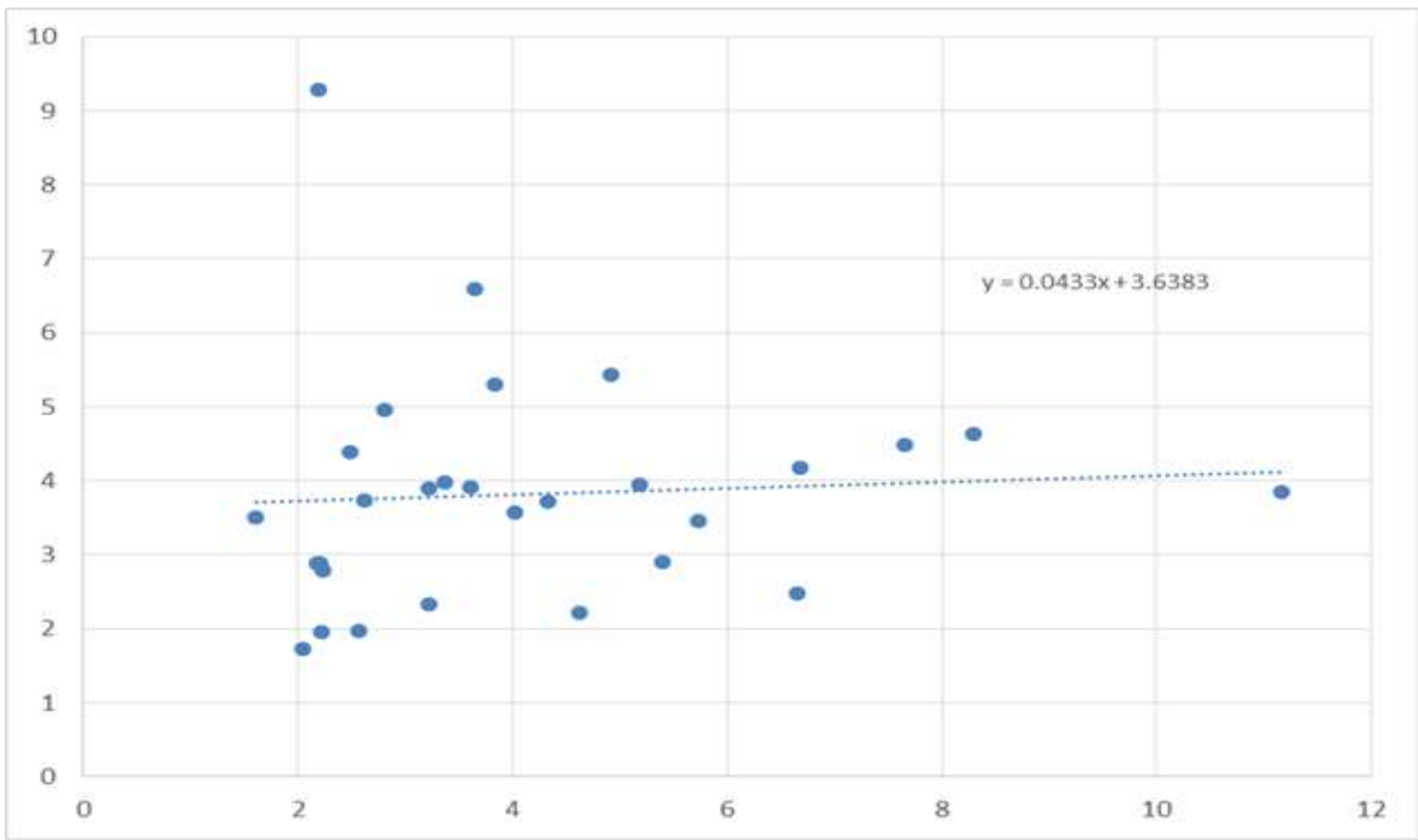

Fig. 4. Long-term inflation and economic growth link in the chosen countries.

To wrap the things up, we can state that GDP influence on inflation is positive, however, quite moderate. In our economy the influence of inflation expectations on inflation is much more significant than that on GDP gap. In short-term period the relation of traditional inflation-economic growth is positive and again moderate. This is proved by the data of other states. 